\title{
Respiratory health surveillance in a toluene di-isocyanate production unit, 1967-97: clinical observations and lung function analyses
}

\author{
M Gerald Ott, Julia E Klees, Sandy L Poche
}

\begin{abstract}
Objectives-To characterise irritant and allergic airway responses and assess changes in forced vital capacity (FVC) and forced expiratory volume in 1 second $\left(F E V_{1}\right)$ relative to exposure to toluene di-isocyanate (TDI).

Methods-Employees $(n=313)$ ever assigned to a TDI production unit for $\geqslant 3$ months (1967-92) were identified from personnel records along with 158 frequency matched referents without known exposure to TDI. Reports made during visits to the occupational clinic of incidents related to exposure to TDI and annual periodic examination results (questionnaire, physical findings, and spirometry) were abstracted and assessed relative to industrial hygiene estimates of
\end{abstract} exposure to TDI.

Results-Mean 8 hour time weighted average estimates of TDI concentrations ranged from $9.9 \mathrm{ppb}$ in jobs with potentially high exposure during the early years of plant operations to $0.5 \mathrm{ppb}$ in jobs with potentially low exposure in more recent years. The corresponding rates of visits to the clinic due to incidents of exposure to TDI (including both irritant and allergic airway responses) declined from 20.5 to 1.0 visits per 100 years of employment at the unit. The annual incidence of asthma induced by TDI declined from $1.8 \%$ before 1980 to $0.7 \%$ afterwards. Neither cross sectional nor longitudinal analyses of FVC and $\mathrm{FEV}_{1}$ showed significant dose-response findings relative to exposure to TDI across the total exposed population. Among cases of occupational asthma there was an apparent initial decline in $F E V_{1}$ within 2 years of first reporting symptoms, but not an accelerated rate of decline in follow up tests from 4-30 years after induction of asthma.

Conclusions-Occurrences of both asthma induced by TDI and irritant airway responses due to exposure to TDI were found in this cohort, but there was no relation between cumulative exposure to TDI and irreversible airflow obstruction as assessed by spirometry.

(Occup Environ Med 2000;57:43-52)

Keywords: toluene di-isocyanate; lung function decrement; occupational asthma
Toluene di-isocyanate (TDI) is an important industrial chemical used in the synthesis of various polyurethane products. Although numerous clinical and epidemiological studies have been conducted to assess the effects of exposure to TDI on respiratory health, many unanswered questions remain, particularly on the effects of long term low level exposure and the relative importance of peak versus cumulative exposure in inducing adverse outcomes. Occurrence of asthma has been evaluated relative to exposure to TDI in occupational health clinics, through large scale surveillance programmes, and in defined employee populations. ${ }^{1-10}$ With few exceptions, reliable exposure data have been lacking to support these investigations. Similarly, lung function decrement has been assessed at various work settings in both cross sectional and longitudinal studies. ${ }^{1411} 12$ The longitudinal studies are generally of better design, but those with more detailed assessments of exposure have been of relatively short duration, mostly in the range of 1-6 years.

The present study was undertaken to assess the respiratory health of employees of a BASF TDI manufacturing unit that began operations in 1967. Although based on existing surveillance records, our approach was based on that used in a 5 year longitudinal study of another TDI manufacturing unit conducted by researchers at Tulane University. ${ }^{10}{ }^{12}$ Three aspects of respiratory health were evaluated in our study: (a) the nature and occurrence of acute respiratory responses after specific incidents of exposure to TDI and phosgene, $(b)$ the induction of allergic airway disease, and (c) irreversible effects on airflow as measured by spirometry.

\section{Methods}

STUDY DESIGN

This study was undertaken at a BASF manufacturing complex in Geismar, Louisiana and is based on personnel, industrial hygiene, and on site occupational health clinic data collected through long standing medical and industrial hygiene surveillance programmes. The TDI unit and referent employees were nested within a larger cohort of 2133 site employees previously studied for mortality. ${ }^{13}$ The study design combined a retrospective cohort approach in identifying participants with a longitudinal assessment of extant medical and exposure records. The objectives and proposed methods were explained to employees and their representatives in a series of meetings before undertaking the study. 
STUDY GROUP AND REFERENTS

The study group included all production and supervisory employees assigned to the TDI unit for $\geqslant 3$ months between its inception in March, 1967 and 30 June 1992. The choice of closing date assured that each participant could potentially be followed up for at least 5 years after initial assignment to the TDI unit. The study group also included maintenance employees working in the unit between 1977 and 1984. Employees assigned only to clerical or administrative staff positions were not considered eligible for the study.

Internal referents were selected from among all other site employees excluding those ever assigned to either the TDI or a diphenylmethane di-isocyanate (MDI) production unit. The referents were frequency matched by pay status when first employed (hourly or non-exempt $v$ exempt salary), race, date of employment, and birth date with one referent selected for every two men in the study group. Referents were selected at random from within the corresponding frequency categories. Because there were few women employees in the study group, twice the number of women referents were selected. A total of 146 men and 22 women were initially chosen as referents. After review of the medical files, 10 of the 168 selected referents were found to have worked with TDI in production, maintenance, or laboratory positions and were shifted to the study group. Thus, 471 employees (313 study group and 158 referents) were included in the study.

ASSESSMENT OF EXPOSURE

The TDI manufacturing operation consisted of processes to convert dinitrotoluene to toluene diamine (TDA), generate phosgene, convert TDA to the di-isocyanate through phosgenation and recover unconsumed phosgene; it included a tank farm and loading operation as well. The processes were run as continuous closed systems. Exposure to TDI was primarily associated with specific activities such as sample collection, breaking down equipment, removing process residues, and tanker or lorry loading. The TDI and phosgene were the two key respiratory hazards of interest.

Initial area sampling for TDI began in 1967 with a Uni-Jet TDI-in-air analyser. Personal sampling based on a paper tape monitoring method (MCA Company, model MCM4000 personal monitor) was begun in $1976 .{ }^{14}$ This method enabled measurement of both peak (averaged over a 9 minute sampling period) and 8 hour time weighted average (TWA) concentrations. Critical reviews of the method are available. ${ }^{15}{ }^{16}$ Starting in 1989 , personal sampling for TDI was performed by Occupational Safety and Health Administration (OSHA) method 42, which uses glass fibre filters coated with 1-(2-pyridyl)piperazine followed by solvent desorption. Samples were analysed for both 2,4- and 2,6-TDI with high performance liquid chromatography (HPLC).

Area sampling for phosgene was initiated in 1967 with an MSA Universal tester. Beginning in 1976, personal samples were collected via an
MDA Company model MCM4020/152 miniature personal monitor. Passive dosimeters were used for immediate assessment of phosgene exposures from 1980 forward. The first dosimeter was developed internally with a commercially available tape impregnated with 4(4'-nitrobenzyl)pyridine (MDA Scientific, Parkridge, IL). ${ }^{17}$

\section{COLLECTION OF CLINICAL DATA}

Each available medical record was reviewed in its entirety and relevant items were extracted from dispensary visit reports and preplacement and periodic medical examinations by two of the study authors (SLP and MGO). Forty records (8.1\%), 16 study group and 24 referents, were not found. Thirty of these records were from people who had left the company before 1980 and eight others from employees who had transferred to other parts of the company.

Visits initiated by the employee

The following items were abstracted from visits to the clinic related to exposure: date of event, chemical substances involved, a description of exposure circumstances, the signs and symptoms reported by the employee and medical treatment rendered, referrals, physician diagnoses, and any recommendations for temporary or permanent removal from the TDI work environment. Qualifying incidents included inhalation exposures regardless of work location and exposures by contact to skin or eyes within the TDI unit.

Identification of cases of occupational asthma For people with asthma-like reactions, we relied primarily on the site physician's assessment of work relatedness as recorded in the medical record. That assessment was most often based on history of symptoms and occasionally included specific measurements of IgE, lung function testing before and after the shift, and referral to outside pulmonologists. There was no indication that specific inhalation challenge (SIC) tests had ever been used to confirm a diagnosis or that bronchial hyperresponsiveness had been evaluated. Temporary or permanent restriction from the unit was decided by a physician. The earliest date, on which symptoms consistent with occupational asthma were reported, was taken to be the onset date for analysis purposes. Generally, the occurrence of a single episode of asthma-like symptoms was not considered sufficient to classify the person as having occupational asthma.

Preplacement and periodic examinations

Health examinations offered when first employed and periodically thereafter included a health questionnaire, clinical laboratory tests, spirometry, and physical examination. A standardised health questionnaire has been used at the site since 1980. Responses to each of four respiratory symptom questions were treated as dichotomous outcome variables. The four questions were: since your last company health evaluation have you had any of the following? 
(1) wheezing in chest, (2) cough lasting over 2 months, (3) chest discomfort with exercise or cold weather, and (4) shortness of breath when walking.

Data on cigarette smoking were extracted from preplacement and periodic examinations and included year started and stopped smoking and average number of cigarettes smoked a day. Year began smoking was that reported on the earliest available smoking history. Cumulative pack-years smoked was calculated as the average number of cigarettes smoked a day multiplied by the years of smoking up to the relevant examination date.

Information was collected on asthma and history of allergy during both preplacement and periodic health examinations. Workers were classified as positive or negative for history of non-occupational asthma when first employed and during employment. The assessment of asthma when first employed was based on the pre-employment examination and reports of childhood asthma on later periodic examinations. A history of hay fever and allergic reactions to foods, pollens, medicines, and injections was similarly abstracted from preplacement and periodic examination questionnaires. Atopy was not assessed by allergy skin tests.

Spirometric data obtained before standardisation of the medical examination programme in 1980, were judged to be unacceptable because of data quality. Consistency in the quality of data improved with the introduction of microprocessor-assisted technology in 1980 (Jones Datamatic Spirometer System, updated in 1989 to a Jones Datamite V System (JONES Medical Instrument, Oak Brook, IL)). For this study, hard copy records of all test results including analog graphic output were individually reviewed by the study investigators and evaluated for reproducibility, duration of expiratory effort, interruptions in flow rate, and other indications of unacceptable test results. On occasion, test performance was poor because of current illness or recent surgery. A computer file was developed of test results including the number of trials and any reasons for unacceptable test performance. The reproducibility requirement for both forced vital capacity (FVC) and forced expiratory volume in 1 second $\left(\mathrm{FEV}_{1}\right)$ was agreement of the two best trials within $5 \%$ or 0.21 . For analysis, the highest FVC and $\mathrm{FEV}_{1}$ value was chosen and could come from different trials. Expiration efforts of $<3$ seconds or before a plateau was reached were considered unacceptable for FVC measurement.

Based on these quality assurance checks, $3.5 \%$ of the spirometry tests were ruled unacceptable because of inadequate test documentation, poor quality of effort, or poor performance of the technician. These results were not included in subsequent statistical analyses. An additional $10.5 \%$ of the tests did not fully meet the reproducibility requirement. Caution is required in excluding such observations because the failure may itself be a measure of less than perfect health. ${ }^{18}$ Within our data set, the reproducibility requirement was less often met among people over the age of 60 , among heavy cigarette smokers, and in general, among people with low FVC or $\mathrm{FEV}_{1}$ values. The requirement was also less often met when $\geqslant 5$ trials were performed indicating that the technician had recognised the poor reproducibility and initiated further trials. Because of potential selection effects, subsequent statistical analyses were run both including and excluding data not meeting the reproducibility requirement.

Regression analyses were also undertaken to evaluate the spirometer effect, performance of the technician, and consistency of results by test date controlling for subject and mean decline in annual lung function. These analyses showed several technicians whose results deviated from average by up to 0.11 and two periods where results deviated by between 0.1 and 0.21 . Again subsequent statistical analyses were run with and without adjustment for differences between technicians and times.

LINKING INDUSTRIAL HYGIENE AND HEALTH DATA A job-exposure matrix approach was used to estimate individual exposure to TDI. Job specific work histories were coded for each person and linked to industrial hygiene measurements through social security numbers, job category, and date. Peak exposure and TWA concentrations were aggregated on a job and time specific basis for three job groups with potentially low, moderate, and high exposure to TDI developed from job descriptions and through reference to a previous study of a TDI unit. $^{10}$ The group with potentially high exposure was made up of operators assigned to TDI loading operations. The group with moderate exposure consisted of operators performing field operations such as sample collection and removing residues from equipment. The group with low exposure included control room operators, supervisory personnel, technicians, and maintenance personnel whose duties involved direct exposure situations less often. Regression analyses were then performed to characterise estimated changes in TWA for each job group over time. For individual sampling results reported as less than a specified value, one half of that value was used in the calculations. Cumulative dose estimates (ppb-months) were computed by multiplying the mean TWA concentration during a particular job assignment by the time spent on that job (expressed in months) and summing across all job assignments. The mean concentration was the concentration predicted by the regression model for the appropriate job group at the midpoint of that job assignment. Computer algorithms were written so that TWA concentrations and cumulative TDI dose could be estimated for each employee as of any given date.

METHODS OF ANALYSIS

Computations were performed with the Statistical Analysis System (SAS), Version 6.12 for PCs. Incidences were calculated with a personyears approach. Cumulative incidence of occupational asthma was also estimated by the 
Kaplan-Meier method. ${ }^{19}$ Risk factors for asthma induced by TDI and irritant effects were investigated with an instantaneous hazard model approach. For questionnaire responses, relations between respiratory symptoms and exposure indices were assessed with a repeated measures procedure that uses generalised estimating equations. The REG procedure in SAS was used in cross sectional analyses of lung function data. The generalised estimating equations model within the GENMOD procedure was used to assess longitudinal lung function data.

\section{Results}

The duration of TDI unit assignments averaged 5.7 and 4.7 years among men and women employees, respectively, with a range of 3 months to 30 years. The study and referent groups were similar in race $(25 \%$ v $27 \%$ black, respectively), percentage salaried ( $8 \%$ in both groups), year and age when first employed. The higher percentage of women in the referent group $(13 \% \quad v 4 \%)$ reflects the previously described sampling strategy. Duration of site employment averaged 15.4 years in the study group and 12.2 years among referents.

EXPOSURE TO TDI

Area sampling in $1967(n=42)$ showed TDI concentrations mostly $<10 \mathrm{ppb}$; concentrations of $25 \mathrm{ppb}$ were detected in the residue handling area. Between 1969 and 1973, TDI concentrations in the reactor, control room, and change house areas were again $<10 \mathrm{ppb}$, with higher concentrations in the residue handling area. Concentrations of 60 to $80 \mathrm{ppb}$ were measured in the distillation area and during tanker loading in 1973.

Personal 8 hour samples collected by the paper tape method from 1976 to the end of 1988 averaged $5.9 \mathrm{ppb}$ TDI $(\mathrm{n}=156)$. Eight hour samples collected by the filter method between 1989 and 1997 averaged 2.8 ppb TDI $(n=84)$. The percentages of 2,4-isomer to total TDI in filter samples ranged from $60 \%$ to $70 \%$, with no remarkable differences relative to season or type of sampling (TWA or task specific). The TWA estimates (mean (SEM)) ranged from 9.9 (1.5) ppb TDI in jobs with potentially high exposure before 1985 to $<1.0$ (0.1) ppb TDI in jobs with potentially low exposure after 1985 (fig 1) and averaged 4.2 ppb TDI across all jobs and times. Regression analyses showed that TWA estimates declined significantly over time for all job groups. The distributions of cumulative dose and average concentration of TDI over a person's entire work career are provided in table 1 .

Positive associations were found between TWAs and both the frequency of peak concentrations $>20 \mathrm{ppb}$ (measured by paper tape method) and the rates of visits to the medical dispensary related to TDI. The frequencies of peak concentrations $>20 \mathrm{ppb}$ were 0.9 and 0.5 per 8 hour shift in jobs with potentially high and moderate exposure, respectively. Between 1967 and 1996, in the whole study group there were 124 self initiated visits to the dispensary attributed to incidents of exposure to TDI. The

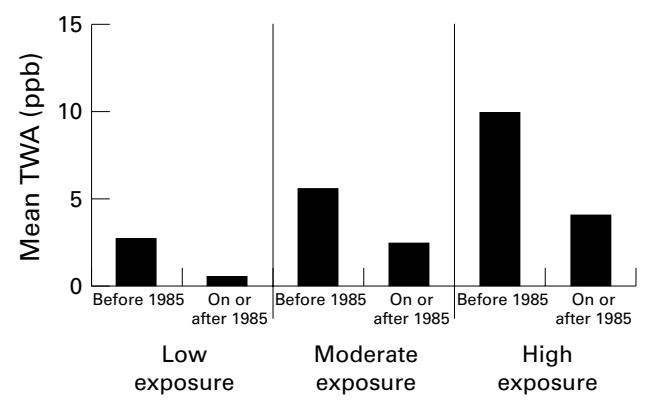

Figure 1 Mean exposure to TDI estimates (8 hour TWA, ppb) by calendar period and job group, 1976-96.

Table 1 Distribution of cumulative dose and TDI concentration averaged over entire exposure period for 313 employees in the study group, 1967-96

\begin{tabular}{lrc}
\hline Exposure measure & $n$ & $\%$ \\
\hline Cumulative TDI dose (ppb-months): & 47 & 15.0 \\
$<50$ & 62 & 19.8 \\
$50-99$ & 98 & 31.3 \\
$100-199$ & 73 & 23.3 \\
$200-499$ & 33 & 10.5 \\
$\geqslant 500$ & & \\
Average TDI concentration across all jobs in the TDI unit \\
(ppb): & 13 & 4.2 \\
$<1.0$ & 113 & 36.1 \\
$1.0-2.9$ & 59 & 18.8 \\
$3.0-4.9$ & 94 & 30.0 \\
$5.0-6.9$ & 34 & 10.9 \\
$\geqslant 7.0$ & & \\
\hline
\end{tabular}

rates of incidents of exposure to TDI per 100 work-years increased with jobs with potentially higher exposure and declined over time in parallel with trends in TWA concentrations. Before 1985, there were $20.5,10.9$, and 3.6 visits related to TDI per 100 work-years in the jobs with potentially high, moderate, and low exposure, respectively. From 1985 onwards, the corresponding rates were $4.6,4.9$, and 1.0 incidents per 100 work-years. Incidents of exposure to TDI were reported by 77 different employees and included 58 incidents related to asthmatic or allergic skin reactions in 29 different workers (19 with asthmatic reactions only, nine with skin allergies only, and one person with both asthma and skin allergies).

There were 46 exposure incidents related to acute TDI inhalation, exclusive of those associated with asthma induced by diisocyanate. Responses ranged from upper airways irritation to a toxic bronchitis. Transport to emergency care occurred with 10 episodes. Possible risk factors for experiencing an acute exposure to TDI through inhalation were evaluated with an instantaneous hazard analysis. The analysis was based on determining the total risk set at the time of each event and accumulating evidence across events in favour or against specific associations. The likelihood of an exposure incident was not statistically related to sex, race, history of non-occupational asthma, hay fever or other allergies, or current level of cigarette smoking. Significant associations were found for job category (higher rates for jobs involving either fieldwork or tanker loading), TDI concentration (expressed as a TWA), age, and duration of employment in the unit (data not shown). Age and duration of employment in the unit were inversely related to risk, that is, risk was 
Table 2 Description of 19 cases of asthma presumed to be induced by TDI

\begin{tabular}{|c|c|c|}
\hline \multirow[b]{2}{*}{ Variables of subjects and exposure } & \multicolumn{2}{|c|}{ Onset of symptoms } \\
\hline & $\begin{array}{l}\text { Before } \\
1980\end{array}$ & $\begin{array}{l}\text { On or } \\
\text { after } \\
1980\end{array}$ \\
\hline \multicolumn{3}{|l|}{ Sex: } \\
\hline Men & 11 & 6 \\
\hline Women & 0 & 2 \\
\hline \multicolumn{3}{|l|}{ Job category: } \\
\hline Field operator & 6 & 5 \\
\hline Maintenance or technician & 3 & 2 \\
\hline TDI loading & 2 & 0 \\
\hline Supervisor & 0 & 1 \\
\hline \multicolumn{3}{|l|}{ Cigarette smoking status } \\
\hline Non-smoker & 9 & 5 \\
\hline Current (<1 pack/day) & 1 & 0 \\
\hline Current ( $\geqslant 1$ pack/day) & 0 & 3 \\
\hline Unknown & 1 & 0 \\
\hline \multicolumn{3}{|l|}{ Basis for case ascertainment: } \\
\hline History of symptoms & 10 & 3 \\
\hline $\begin{array}{l}\text { History of symptoms }+ \text { pulmonologist } \\
\text { evaluation }\end{array}$ & 1 & 2 \\
\hline $\begin{array}{l}\text { History of symptoms+shift in PFTs } \\
\text { before to after }\end{array}$ & 0 & 3 \\
\hline \multicolumn{3}{|l|}{ Earlier exposure to TDI or phosgene: } \\
\hline None & 8 & 2 \\
\hline TDI & 1 & 3 \\
\hline Phosgene & 0 & 2 \\
\hline Phosgene and TDI & 2 & 1 \\
\hline \multicolumn{3}{|c|}{ Duration of earlier TDI exposure (months): } \\
\hline $2-11$ & 5 & 2 \\
\hline $12-35$ & 4 & 3 \\
\hline $36-59$ & 1 & 2 \\
\hline$\geqslant 60$ & 1 & 1 \\
\hline \multicolumn{3}{|c|}{ Duration of exposure after onset of symptoms (y): } \\
\hline$<0.5$ & 8 & 4 \\
\hline $0.5-0.9$ & 1 & 3 \\
\hline $1.0-1.9$ & 1 & 1 \\
\hline$\geqslant 2.0$ & 1 & 0 \\
\hline
\end{tabular}

higher for younger workers and those with fewer years of unit service.

EXPOSURE TO PHOSGENE

Phosgene concentrations were mostly below the $0.05 \mathrm{ppm}$ limit of measurement (area samples, 1967-73). Eight hour personal samples $(\mathrm{n}=42)$ collected between 1977 and 1988 averaged $0.007 \mathrm{ppm}$ phosgene with a maximum TWA concentration of $0.04 \mathrm{ppm}$. No significant statistical trends were found relative to either job category or year of sampling.

There were 176 incidents of exposure to phosgene between 1967 and 1996, 152 of which were reported by employees of the TDI unit. Transport to emergency care occurred in 39 instances. Two cases experienced pulmonary oedema, one of which resulted in death. Analyses of correlates of cases versus non-cases again showed that risk decreased with increasing age and longer total employment. The incident rate while working at the TDI unit was 9.5 incidents per 100 work-years before 1985, and 3.4 after. Highest rates of incidents occurred for the job group field operator with 12.7 incidents per 100 work-years at risk before 1985, and 5.6 after. Phosgene badge readings obtained during 20 of the reported exposure incidents showed concentrations $<2.5$ ppmminutes in $40 \%$ of the incidents and $2.5-9.9$ ppm-minutes in $35 \%$ of the incidents. The remaining readings were $>10$ ppm-minutes.

ASTHMA INDUCED BY DI-ISOCYANATE

The review of medical records identified 19 presumed cases of asthma induced by TDI ( $6.4 \%$ of all study group subjects with available
Table 3 Risk factors for developing asthma presumed to be induced by TDI (analysis based on conditional logistic regression with backward elimination)

\begin{tabular}{|c|c|c|}
\hline Explanatory variables * & $\begin{array}{l}\text { Risk } \\
\text { ratio }\end{array}$ & $95 \% C I$ \\
\hline Earlier exposure to TDI (yes $=1$, no $=0$ ) & 3.1 & 1.1 to 9.0 \\
\hline $\begin{array}{l}\text { Earlier exposure to phosgene (yes }=1 \text {, } \\
\text { no }=0 \text { ) }\end{array}$ & 4.3 & 1.3 to 15.7 \\
\hline Current cigarette smoking (packs/day) & 0.4 & 0.1 to 1.0 \\
\hline Duration of exposure (y) & 0.8 & 0.7 to 0.9 \\
\hline
\end{tabular}

*Three variables, intensity of exposure to TDI (8-h TWA), earlier exposure by inhalation to any respiratory irritant other than TDI, and sex were NS at $\mathrm{p}<0.05$.

medical records). An additional employee developed asthma induced by MDI after an exposure incident in the MDI unit, but thereafter experienced asthmatic reactions in the presence of very low TDI concentrations. This person had previously worked in the TDI unit for 5 years without asthmatic symptoms.

Selected characteristics of the 19 cases of asthma induced by TDI are summarised in table 2 . In 11 cases, asthmatic symptoms were first reported before 1980. Six cases occurred among employees who were part of the initial workforce at the TDI unit in 1967. Eleven cases held field operator positions and two were assigned to tanker loading at the time of the start of symptoms. The six remaining cases had been assigned to maintenance (three cases), plant supervision (one case), instrumentation (one case), or laboratory analysis (one case).

As well as the cross sensitisation case already described, a second person reported multiple episodes of asthmatic reactions related to very low exposures to TDI. This employee had remained in the TDI unit for $>2$ years after first reporting symptoms. Initially, he experienced a delayed asthmatic response. Later, he reported an immediate response with symptoms including nasal congestion, wheezing, and thick foamy mucus production. After reassignment, he experienced several severe asthmatic episodes associated with very low concentrations of TDI. One episode occurred while attending a training session in a TDI office area.

A conditional logistic regression analysis was performed to evaluate potential risk factors for developing asthma induced by TDI (table 3 ). Four factors were statistically related to risk of asthma at the 0.05 significance level. These were: (a) previous incident of exposure to TDI, (b) previous incident of exposure to phosgene resulting in admission to hospital, coughing, chest pain, or difficulty in breathing, (c) current level of cigarette smoking (inversely related to risk), and (d) duration of previous exposure to TDI (also inversely related to risk), These findings are based on very small numbers of cases. For example, only five of 19 cases had reported previous incidents of exposure to phosgene, and seven had experienced previous incidents of exposure to TDI. Two of the TDI incidents related to rashes that had developed while handling TDI or waste products containing TDI.

The yearly incidence of asthma induced by TDI cases was $1.1 \%$ (19 cases in 1779 TDI unit work-years), but was higher before 1980 (1.8\%) than after $1979(0.7 \%)$. The cumulative 
Table 4 Explanatory factors for selected respiratory symptoms reported over an 18 year period among employees exposed to TDI and referents (multivariate logistic regression model, generalised estimating equation approach)

\begin{tabular}{lll}
\hline Respiratory symptom and covariate & $\begin{array}{l}\text { Risk } \\
\text { ratio }\end{array}$ & 95\% CI \\
\hline Wheezing in chest (n=138): & & \\
$\quad$ Cigarettes (packs/day) & 3.4 & 2.0 to 5.7 \\
$\quad$ History of non-occupational asthma & 3.4 & 1.5 to 8.0 \\
$\quad$ Asthma induced by di-isocyanate & 8.8 & 4.0 to 19.4 \\
$\quad$ Exposed to TDI $v$ referents & 0.8 & 0.4 to 1.5 \\
Cough lasting 2 months (n=37): & & \\
$\quad$ Cigarettes (packs/day) & 2.2 & 1.3 to 3.7 \\
$\quad$ History of non-occupational asthma & 0.7 & 0.1 to 3.3 \\
$\quad$ Asthma induced by di-isocyanate & 0.8 & 0.1 to 5.5 \\
$\quad$ Exposed to TDI $v$ referents & 0.9 & 0.4 to 2.2 \\
Chest pain on exercise (n=63): & & \\
$\quad$ Cigarettes (packs/day) & 1.0 & 0.5 to 2.0 \\
$\quad$ History of non-occupational asthma & 2.9 & 0.5 to 14.9 \\
$\quad$ Asthma induced by di-isocyanate & 4.2 & 1.6 to 10.7 \\
$\quad$ Exposed to TDI $v$ referents & 0.7 & 0.3 to 1.9 \\
Shortness of breath (n=59): & & \\
$\quad$ Cigarettes (packs/day) & 1.4 & 0.8 to 2.3 \\
$\quad$ History of non-occupational asthma & 1.6 & 0.5 to 5.6 \\
$\quad$ Asthma induced by di-isocyanate & 1.7 & 0.6 to 4.8 \\
$\quad$ Exposed to TDI $v$ referents & 1.1 & 0.5 to 2.4 \\
One or more symptoms (n=232): & & \\
$\quad$ Cigarettes (packs/day) & 2.4 & 1.6 to 3.6 \\
$\quad$ History of non-occupational asthma & 3.0 & 1.3 to 6.7 \\
$\quad$ Asthma induced by di-isocyanate & 4.2 & 2.1 to 8.4 \\
$\quad$ Exposed to TDI $v$ referents & 0.8 & 0.4 to 1.3 \\
\end{tabular}

^Based on 2677 periodic examinations, sex included as covariate (data not shown).

incidence for people assigned to the TDI unit for at least 20 years was estimated by the Kaplan-Meier method to be $11.5 \%$ (95\% CI 5.3 to $17.7 \%$ ).

MEDICAL EXAMINATION FINDINGS

Cigarette smoking and history of nonoccupational asthma were available for $87 \%$ and $89 \%$ of all employees and $97 \%$ and $99 \%$ of the 395 employees employed at any time after 1979. The percentage of ever cigarette smokers was $68 \%$ within the study group and $58 \%$ among referents. A higher percentage of referents reported a history of asthma before employment $(8.5 \%$ v $2.4 \%)$. There were no remarkable differences between the two groups in reporting a history of hay fever $(3.9 \% v$ $4.4 \%$ ) or other allergies excluding asthma when first employed $(7.0 \%$ v $7.2 \%)$.

Study and referent employees completed 2677 periodic questionnaires up to mid-1997. Data were not available for the 76 employees who had left active employment before 1980 . Between one and 18 questionnaires were completed by $363(92 \%)$ of the remaining 395 employees. From 1980 forward, yearly participation in the examination programme averaged $61 \%$ of referents and $60 \%$ of exposed employees.

In table 4 , the results of logistic regression analyses for respiratory symptoms are summarised for four explanatory factors. Positive response percentages ranged from $1.4 \%$ (37 of 2677) for cough lasting 2 months to $5.2 \%$ for wheezing in the chest. Cigarette smoking was associated with wheezing in chest, cough lasting 2 months, and reporting one or more symptoms of the airways. History of nonoccupational asthma was associated with wheezing in the chest and reporting one or more airways symptoms, but not with chronic cough. A similar symptom pattern was found for employees with asthma induced by diisocyanate. Among these workers, most of the data from the questionnaires $(79 \%)$ pertained to examinations after restriction from the TDI unit. There was no trend in the percentage of positive responses to wheezing in the chest (17\%, overall) for before versus after exposure; for the period $\geqslant 5$ years after diagnosis, the positive response rate for wheezing in the chest was $16 \%$. Three cases reported routine use of asthma medications after assignment to other work areas. No significant associations with responses in the questionnaires were found for those exposed to TDI versus referents, in analyses in which asthma induced by diisocyanate was or was not included as a covariate. When cases of both non-occupational and occupational asthma were removed from the analyses, there were again no significant differences between the exposed and referent groups.

SPIROMETRY

One or more lung function tests were available for 371 (94\%) of 395 employees employed on or after 1 January 1980 . The average number of tests per employee was 7.5 and the average interval between the earliest and most recent test was 9.3 years.

An initial cross sectional analysis was carried out with the earliest available lung function test to determine if previous exposure to TDI was associated with $\mathrm{FVC}, \mathrm{FEV}_{1}$, and $\mathrm{FEV}_{1} / \mathrm{FVC} \%$ (data not shown). The average age of employees at the time of testing was 35.6 years. The mean dose of TDI was 148 ppb-months with a range up to $983 \mathrm{ppb}$-months. The dose of TDI was forced into the model with other factors selected by backward elimination at a 0.05 significance level. These factors included age, height, race, sex, cigarette pack-years, concentration of TDI (TWA), history of nonoccupational asthma, history of allergies except asthma, previous incident of exposure to phosgene with symptoms, and, finally, previous asthma induced by di-isocyanate. Age, height, race, and sex were significant predictors of FVC and $\mathrm{FEV}_{1}$. Both cigarette pack-years and a history of non-occupational asthma were significant explanatory factors for $\mathrm{FEV}_{1}$ and $\mathrm{FEV}_{1} / \mathrm{FVC} \%$, but not for FVC. Neither TDI concentration nor cumulative dose was significantly related to any of the three lung function variables. Analyses restricted to observations meeting the reproducibility requirement and adjusted for effects of technicians and time yielded the same non-significant results relative to TDI concentration and cumulative dose.

Identical cross sectional analyses were carried out with the most recent lung function test (table 5). Mean TDI dose had increased to 234 ppb-months and average age to 44.8 years. Age, height, race, and sex were significant predictors of FVC and $\mathrm{FEV}_{1}$ as before and pack years smoked, which had increased to an average of 14.3 pack-years, was a significant risk factor for FVC, $\mathrm{FEV}_{1}$, and $\mathrm{FEV}_{1} / \mathrm{FVC} \%$. A history of non-occupational asthma remained a significant predictor of $\mathrm{FEV}_{1}$ and $\mathrm{FEV}_{1} / \mathrm{FVC} \%$. The occurrence of previous incidents of exposure to 
Table 5 Regression of FVC, FEV ${ }_{1}$, and $F E V_{1} / F V C \%$ on selected explanatory factors based on most recent spirometry test for 371 employees

\begin{tabular}{|c|c|c|c|c|c|c|c|}
\hline \multicolumn{2}{|l|}{ Explanatory factor } & \multicolumn{2}{|l|}{$F V C$} & \multicolumn{2}{|l|}{$F E V_{1}$} & \multicolumn{2}{|l|}{$F E V_{1} / F V C$} \\
\hline Parameter & Mean & $\beta$ & SEM & $\beta$ & $S E M$ & $\beta$ & $S E M$ \\
\hline \multicolumn{8}{|l|}{ Occupational factors: } \\
\hline TDI dose (ppb-months) $\dagger$ & $234.2 \ddagger$ & 0.00009 & 0.00013 & 0.00013 & 0.00011 & 0.00001 & 0.000014 \\
\hline Acute exposure to phosgene (\%) & 11.3 & $-0.257^{\star \star}$ & 0.0938 & $-0.241^{\star \star}$ & 0.0809 & - & - \\
\hline Occupational asthma (\%) & 4.6 & - & - & - & - & $-0.042^{\star \star}$ & 0.0157 \\
\hline \multicolumn{8}{|l|}{ Non-occupational factors: } \\
\hline Age $(\mathrm{y})$ & 44.8 & $-0.029^{\star \star \star}$ & 0.0031 & $-0.030^{\star \star \star}$ & 0.0027 & $-0.002^{\star \star \star}$ & 0.0003 \\
\hline Height $(\mathrm{cm})$ & 177.1 & $0.054^{\star \star \star}$ & 0.0044 & $0.040^{\star \star \star}$ & 0.0038 & $-0.001^{\star}$ & 0.0005 \\
\hline Race (\% black) & 28.6 & $-0.681^{\star \star \star}$ & 0.0650 & $-0.485^{\star \star \star}$ & 0.0560 & - & - \\
\hline Sex (\% women) & 6.7 & $-0.451^{\star \star \star}$ & 0.1271 & $-0.364^{\star \star \star}$ & 0.1097 & - & - \\
\hline Cigarettes (pack-years) & 14.3 & $-0.004^{\star}$ & 0.0017 & $-0.006^{\star \star \star}$ & 0.0014 & $-0.001^{\star \star \star}$ & 0.0002 \\
\hline $\begin{array}{l}\text { History of non-occupational } \\
\text { asthma }(\%)\end{array}$ & 6.2 & - & - & $-0.260^{\star}$ & 0.1046 & $-0.063^{\star \star \star}$ & 0.0136 \\
\hline
\end{tabular}

${ }^{\star} \mathrm{p}<0.05 ;{ }^{\star \star} \mathrm{p}<0.01 ;{ }^{\star \star \star}{ }^{\star} \mathrm{p}<0.001$.

†TDI dose forced into model, other factors included based on backward selection with $\mathrm{p}<0.05$.

$\ddagger$ Mean dose in 267 TDI unit employees.

phosgene was associated with declines in both FVC and $\mathrm{FEV}_{1}$ and occupational asthma was associated with a decline in $\mathrm{FEV}_{1} / \mathrm{FVC} \%$. The TDI concentration and cumulative dose were not significant predictive factors in the full model or in models without occupational asthma as a covariate. The same results were obtained in the restricted analyses. An additional set of analyses carried out for 119 never smokers also found no significant relation between outcome of spirometry and either TDI concentration or dose (data not shown).

Longitudinal analyses (table 6) were performed to estimate the annual change in FVC and $\mathrm{FEV}_{1}$ for various subgroups of the population with $\geqslant 3$ lung function tests covering an interval of $\geqslant 2$ years. For men the average annual decline in FVC and $\mathrm{FEV}_{1}$ was 0.036 and $0.0371 / \mathrm{y}$, respectively and for women employees the average annual declines were 0.019 and $0.0231 / y$. The declines in FVC and $\mathrm{FEV}_{1}$ were greater among cigarette smokers than never smokers. The annual decrements in FVC and $\mathrm{FEV}_{1}$ among people with a history of non-occupational or occupational asthma were unremarkable; however, baseline $\mathrm{FEV}_{1}$ was lower by about 0.31 for both subgroups relative to that of other men in the study.

Differences in annual FVC and $\mathrm{FEV}_{1}$ decrements between exposed and referent groups were evaluated by including exposure as an explanatory factor for slope in the regression model. Separate analyses were performed for men and women employees and for men who never smoked cigarettes and those who accumulated $\geqslant 20$ pack-years of cigarette smoking. Among men, annual FVC and $\mathrm{FEV}_{1}$ decrements were not significantly associated with exposure, consistent with the small slope differences between exposed workers and referents reported in table 6 . Among women, there was a significant difference $(p=0.03)$ between exposed and referent women in the rate of $\mathrm{FEV}_{1}$ decline. This finding is based on observations for only 10 exposed (average decrement: $0.027 \mathrm{l} / \mathrm{y}$ ) and 12 referent women (average decrement: 0.014 1/y). Average packyears smoked was much higher among TDI exposed women than referents (14.8 $v 4.6$ pack-years) and follow up interval was nearly 5 years longer among women in the TDI group.

Additional modelling of factors potentially influencing annual FVC and $\mathrm{FEV}_{1}$ decrements is summarised in table 7 for the total population and people who never smoked cigarettes. In general, the annual rate of decline in FVC and $\mathrm{FEV}_{1}$ was less among women and black people. Among non-smokers the rate of decline in FVC and $\mathrm{FEV}_{1}$ accelerated with increasing age. For the total population, FVC, and in particular $\mathrm{FEV}_{1}$ decrements accelerated with increased pack-years smoked. Relative change in body mass index (BMI) was also an important predictive factor for change in the rate of FVC decline, and to a lesser extent, was related to change in the rate of $\mathrm{FEV}_{1}$ decline.

Table 6 Estimated annual change in FVC and FEV, in selected subgroups of the population based on generalised estimating equation (GEE) analysis approach

\begin{tabular}{|c|c|c|c|c|c|c|}
\hline \multirow[b]{2}{*}{ Population subgroup } & \multirow[b]{2}{*}{$n$} & \multirow[b]{2}{*}{ PFTs $n$} & \multicolumn{2}{|l|}{$F V C$} & \multicolumn{2}{|l|}{$F E V_{1}$} \\
\hline & & & Baseline (l) & Slope estimate $(95 \%$ CI) (l/y) & Baseline (l) & Slope estimate (95\% CI) (l/y) \\
\hline Total group & 296 & 2641 & 4.68 & $-0.035(-0.031$ to -0.039$)$ & 3.76 & $-0.036(-0.033$ to -0.039$)$ \\
\hline Women & 22 & 169 & 3.58 & $-0.019^{\star}(-0.011$ to -0.026$)$ & 2.97 & $-0.023(-0.017$ to -0.029$)$ \\
\hline Exposed & 10 & 88 & 3.62 & $-0.020^{\star}(-0.016$ to -0.024$)$ & 3.07 & $-0.027(-0.022$ to -0.032$)$ \\
\hline Referents & 12 & 81 & 3.55 & $-0.014(0.004$ to -0.033$)$ & 2.89 & $-0.014(-0.006$ to -0.022$)$ \\
\hline Men & 274 & 2472 & 4.77 & $-0.036(-0.032$ to -0.040$)$ & 3.82 & $-0.037(-0.033$ to -0.040$)$ \\
\hline Exposed & 209 & 1866 & 4.83 & $-0.037(-0.033$ to -0.042$)$ & 3.87 & $-0.037(-0.033$ to -0.041$)$ \\
\hline Referents & 65 & 606 & 4.59 & $-0.034(-0.027$ to -0.041$)$ & 3.67 & $-0.035(-0.028$ to -0.042$)$ \\
\hline Men, never smokers & 92 & 862 & 4.76 & $-0.033(-0.026$ to -0.041$)$ & 3.85 & $-0.033(-0.027$ to -0.039$)$ \\
\hline Exposed & 67 & 620 & 4.82 & $-0.033^{\star}(-0.024$ to -0.041$)$ & 3.89 & $-0.031^{\star}(-0.024$ to -0.039$)$ \\
\hline Referents & 25 & 242 & 4.62 & $-0.034^{\star}(-0.022$ to -0.047$)$ & 3.74 & $-0.036^{\star}(-0.028$ to -0.043$)$ \\
\hline Men $(\geqslant 20$ cigarette pack-years $)$ & 96 & 855 & 4.60 & $-0.043(-0.037$ to -0.049$)$ & 3.59 & $-0.044(-0.039$ to -0.049$)$ \\
\hline Exposed & 72 & 637 & 4.70 & $-0.044(-0.036$ to -0.053$)$ & 3.70 & $-0.043(-0.038$ to -0.049$)$ \\
\hline Referents & 24 & 218 & 4.29 & $-0.041(-0.031$ to -0.051$)$ & 3.28 & $-0.044(-0.034$ to -0.055$)$ \\
\hline Men with non-occupational asthma & 19 & 184 & 4.58 & $-0.028(-0.011$ to -0.046$)$ & 3.49 & $-0.031^{\star}(-0.017$ to -0.044$)$ \\
\hline Men with occupational asthma & 15 & 142 & 4.70 & $-0.037(-0.026$ to -0.049$)$ & 3.58 & $-0.034(-0.023$ to -0.045$)$ \\
\hline
\end{tabular}

^Non-convergence of GEE estimates after 50 iterations. 
Table 7 Linear regression of factors modifying annual change in FVC and FEV, analysis based on generalised estimating equation approach among 296 exposed and referent employees

\begin{tabular}{lll}
\hline $\begin{array}{l}\text { Population subgroup } \\
\text { and explanatory factors }\end{array}$ & FVC estimate (95\% CI) (l/y) & FEV estimate (95\% CI) (l/y) \\
\hline Total group (n=296): & & \\
Slope & $-0.043^{\star \star \star}(-0.030$ to -0.056$)$ & $-0.043^{\star \star \star}(-0.031$ to -0.056$)$ \\
Slope $\times s e x$ & $0.018^{\star \star \star}(0.008$ to 0.029$)$ & $0.012^{\star}(0.001$ to 0.022$)$ \\
Slope $\times$ race & $0.005(-0.003$ to 0.012$)$ & $0.008^{\star \star}(0.002$ to 0.014$)$ \\
Slope $\times$ pack-years & $-0.0003^{\star \star}(-0.0001$ to -0.0005$)$ & $-0.0003^{\star \star \star}(-0.0001$ to -0.0004$)$ \\
Slope $\times$ BMI & $-0.037^{\star \star \star}(-0.019$ to -0.054$)$ & $-0.024^{\star \star}(-0.008$ to -0.040$)$ \\
Slope $\times$ TDI dose & $-0.00001(-0.00002$ to 0.00001$)$ & $0.00000(-0.00001$ to 0.00001$)$ \\
Never cigarette smokers $(\mathrm{n}=101):$ & \\
Slope & $-0.031^{\star \star}(-0.008$ to -0.055$)$ & $-0.028^{\star}(-0.006$ to -0.051$)$ \\
Slope $\times$ sex & $0.020^{\star}(0.003$ to 0.037$)$ & $0.011(-0.005$ to 0.028$)$ \\
Slope $\times$ race & $0.006(-0.005$ to 0.017$)$ & $0.004(-0.006$ to 0.014$)$ \\
Slope $\times a g e$ & $-0.0012^{\star \star \star}(-0.0005$ to -0.0019$)$ & $-0.0011^{\star \star \star}(-0.0005$ to -0.0018$)$ \\
Slope $\times$ BMI & $-0.055^{\star \star \star}(-0.022$ to -0.087$)$ & $-0.030(-0.063$ to 0.003$)$ \\
Slope $\times$ TDI dose & $-0.00002(-0.00004$ to 0.00000$)$ & $-0.00000(-0.00003$ to 0.00001$)$ \\
\hline
\end{tabular}

${ }^{\star} \mathrm{p}<0.05 ;{ }^{\star \star} \mathrm{p}<0.01 ;{ }^{\star \star \star}{ }^{\mathrm{p}} \mathrm{p}<0.001$

Factor definitions: sex, woman $=1$ man $=0$; race, black $=1$ other $=0$; age $=<40$ at last examination; pack-years=number of cigarette pack-years at last examination; BMI=average annual gain in BMI $\left(\mathrm{kg} / \mathrm{m}^{2}\right)$ between first and last examination; TDI dose=cumulative TDI dose in ppb-months at last examination.

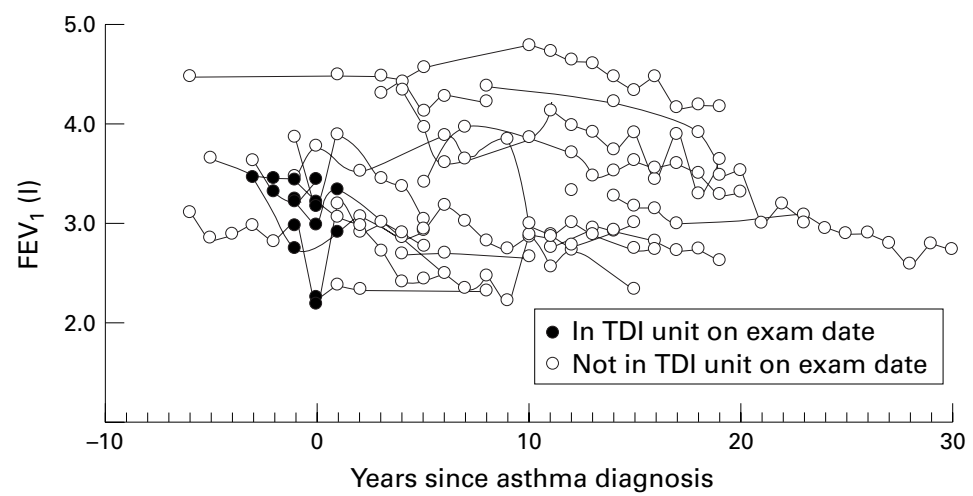

Figure 2 Scatter plot of FEV readings by interval (years) since diagnosis of asthma for 18 employees with asthma induced by di-isocyanate.

Cumulative dose of TDI was not significantly related to the annual decline in either FVC or $\mathrm{FEV}_{1}$. Analyses restricted to people with at least five spirometry tests and tracings meeting all quality assurance requirements yielded the same results for TDI dose; $p$ values were marginally different for some of the remaining covariates (data not shown).

Lung function data were also evaluated for 18 employees who developed asthma induced by di-isocyanate. For eight employees, with data available before first reported symptoms of asthma, values of $\mathrm{FEV}_{1}$ averaged 0.031 below expectation. Among five employees tested while working in the unit and within 2 years of first reporting asthmatic symptoms, $\mathrm{FEV}_{1}$ averaged 0.441 below expectation. Similar results were found for workers who remained in the unit for up to 2 years after symptoms were reported. Individual data points for $\mathrm{FEV}_{1}$ before, during, and after exposure to TDI are plotted in figure 2. On average, the interval between date of initial symptoms of asthma and the most recent lung function test was 13.8 years (range $4-30$ years). Most cases were reassigned to other work areas within a year of reporting asthmatic symptoms, but remained employees of the company.

\section{Discussion}

Nineteen cases of asthma presumed to be induced by TDI $(6.4 \%)$ were identified over a
30 year observation period in this cohort. Because cases were not confirmed by SIC, it is possible that overestimation occurred. In one recent study of 114 isocyanate workers referred for evaluation of respiratory complaints, ${ }^{20} 46$ were found to have a work related pattern of asthma symptoms, but only 14 of these men could be confirmed to have occupational asthma by SIC. Thirty of the 46 workers had positive methacholine challenge tests. ${ }^{20}$ In a second study, asthma was confirmed by SIC in only $41 \%$ of workers exposed to TDI that were referred because of probable occupational asthma. ${ }^{21}$ Among workers with positive SIC, $78 \%$ had positive methacholine responses; however, among people with negative SIC, $46 \%$ were positive by the methacholine challenge test. Thus, differentiation between people with bronchial hyperresponsiveness and those with occupational asthma confirmed by SIC could be difficult when relying on history alone. Because the total population at risk was not studied, it cannot be determined from these referral studies whether or not bronchial hyperresponsiveness is itself an outcome of long term exposure to TDI. However, Jones et al had not found a relation between exposure to TDI and methacholine challenge test results among people employed in the polyurethane foam industry. ${ }^{4}$

True cases could have been missed as we relied on self reported histories of symptoms and employees may have left the TDI unit without reporting symptoms to the health clinic or may have been reassigned on a precautionary basis. Additionally, there may have been insufficient detail in the medical records to enable case status to be accurately determined. Underascertainment is less likely among long term employees at the unit because asthmatic people who continue to work in exposed areas often develop increasingly severe symptoms.

The annual incidence of asthma induced by TDI found in our study (range $0.7 \%-1.8 \%$ ) was comparable with that in other similar investigations in TDI manufacture ${ }^{10}$ and in polyurethane foam operations, ${ }^{4}$ where TDI concentrations were in the same range as the present study. Our study most closely parallels the Tulane study. ${ }^{10}{ }^{12}$ During comparable observation periods in the mid to late 1970s, TWA estimates for TDI were somewhat higher for the Geismar unit. Since then, TDI concentrations have declined steadily in our unit. Twelve of 277 employees (4.3\%) included in the Tulane study became clinically "sensitive", ${ }^{10}$ nine cases developed within 1 year of first exposure and six cases had been subject to high short term exposures during spills of TDI. No mention was made of acute exposures to other respiratory irritants.

In our study, cases also tended to occur among newly recruited employees and to be associated with previous exposure to incidents of exposure to TDI (seven cases). Also, cases were linked to previous incidents of acute exposure to phosgene (five cases). The phosgene finding could be a chance occurrence. It might also be that a disproportionate share of 
people, who experienced respiratory symptoms after exposure to phosgene, had pre-existing bronchial hyperresponsiveness or that the exposure incident induced bronchial hyperresponsiveness or other changes in the respiratory tract that increased the likelihood of developing asthmatic responses during exposure to TDI. Acute chlorine exposures resulting in severe respiratory symptoms have been found to produce both transient increases in bronchial hyperresponsiveness and transient decreases in airway function. ${ }^{22}$ Because our cases of asthma were diagnosed by history of symptoms and were not confirmed by SIC, the case group may include people with underlying bronchial hyperresponsiveness but not immunologically mediated asthma. Such a selection mechanism might also partly explain why potential cases of asthma induced by diisocyanate referred to specialty clinics ${ }^{20} 21$ often test positive on methacholine challenge, but negative on SIC.

In both cross sectional and longitudinal analyses covering an 18 year follow up period, we found no convincing evidence linking lung function decrement to cumulative dose or average TDI concentration. For a subset of people found to have asthma induced by di-isocyanate, there was a significant decline in the average $\mathrm{FEV}_{1} / \mathrm{FVC} \%$ in their most recent test. A relative decline in $\mathrm{FEV}_{1}$ had been noted among cases actively working in exposure areas and tested within 2 years of first reporting asthmatic symptoms. Longitudinal analysis of FVC and $\mathrm{FEV}_{1}$ trends among cases of occupational asthma was unremarkable; the average annual $\mathrm{FEV}_{1}$ decrement of $0.038 \mathrm{1} / \mathrm{y}$ was the same as the average decrement among all study participants.

In the Tulane study, cumulative dose treated as a continuous variable was also not significantly related to annual FVC or $\mathrm{FEV}_{1}$ decrements. ${ }^{10}$ However, a significant effect on the rate of $\mathrm{FEV}_{1}$ decrement was found with a dichotomous dose measure (TDI dose above $v$ below 68 ppb-months) with a larger relative decrement found for never cigarette smokers. ${ }^{10}$ In our study, subanalyses restricted to never cigarette smokers did not show significant trends in annual FVC or $\mathrm{FEV}_{1}$ decrements relative to dose of TDI.

As our lung function testing programme was not carried out as part of a research effort and in true prospective modality, there was undoubtedly less tight control over data quality than might have been the case otherwise. However, all individual data were audited and the analysis findings were robust for reproducibility requirement and adjustments for effects of technicians and time. Furthermore, our estimates of the effects of various covariates on lung function seem to be consistent with published findings. For example, in a cross sectional analysis of never smokers, the estimated age effect on $\mathrm{FEV}_{1}$ of $-0.0261 / \mathrm{y}$ was in the midrange of predicted values $(-0.021$ to $-0.0321) .{ }^{18}$ Our longitudinally based estimates of annual change in $\mathrm{FEV}_{1}$ of -0.037 and $-0.0231 / y$ for men and women, respectively, are in agreement with estimates of -0.035 and
$-0.0241 / y$ in asymptomatic non-smoking men and women from a general population for comparable age categories. ${ }^{23}$ The effect of pack-years smoked on $\mathrm{FEV}_{1}$ and $\mathrm{FEV}_{1} / \mathrm{FVC} \%$ was also readily detectable in both our cross sectional and longitudinal analyses. Finally, we detected effects of weight gain on longitudinal changes in FVC and $\mathrm{FEV}_{1}$ comparable with those reported by Wang et $a l^{24}$ and observed declines in $\mathrm{FEV}_{1}$ among asthmatic people, but of a lesser magnitude than reported by Lange $e t$ $a l .{ }^{25}$

The lack of lung function tests before 1980 is a concern because exposure to TDIs was known to have been higher before than after that date. Of the 190 employees with jobs in the TDI unit before 1980, 39 had left active employment by 1980 . It is not known whether or not this group of former employees differentially included people whose respiratory health was affected by exposure. However, lung function analyses, that included 145 of the remaining 151 people exposed during that period, showed no relation between cumulative exposure and either FVC or $\mathrm{FEV}_{1}$. Also, review of mortality follow up to the end of 1992 for the total Geismar cohort $^{13}$ did not identify any deaths from respiratory disease among employees in the TDI unit who had ended employment before 1980. Review of employment records also did not provide evidence of leaving employment due to poor respiratory health.

An additional consideration is that in past years there may have been reluctance to assign employees to the TDI unit who had preexisting respiratory conditions. A history of non-occupational asthma, mostly noted as childhood asthma, was reported by $8.3 \%$ of the referents and only $2.5 \%$ of the employees in the TDI unit with spirometry data. Also, the mean FVC and $\mathrm{FEV}_{1}$ measurements were about 0.21 lower in referents than in employees of the TDI unit at baseline. There was no notable difference in pack-years smoked between the two groups except that cigarette smoking was more common among exposed than referent women. Because there was no evidence of a TDI dose-response relation based on final $\mathrm{FVC}$ and $\mathrm{FEV}_{1}$ measurements and no relation between annual decrements in FVC or $\mathrm{FEV}_{1}$ and dose of TDI, it is unlikely that initial selection effects would have obscured irreversible effects on lung function related to exposure to TDI.

In summary, this study provides cross sectional and longitudinal lung function data for workers exposed to TDI over a longer time frame than was previously available. In agreement with other studies conducted in workplaces with exposures ranging up to $5 \mathrm{ppb}$ TWA and where active medical surveillance and exposure monitoring programmes were in place, ${ }^{4101126}$ we found little evidence of a relation between exposure to TDI and either FVC or $\mathrm{FEV}_{1}$ decrement. Routine medical surveillance is recommended to assure early detection and evaluation of workers experiencing asthmatic reactions to di-isocyanates. 
We thank Dr Wolfgang Hartz, former Corporate Medical Director of BASF Corporation, for his efforts to develop a Zober and Dr Klaus Strassburger of BASF AG for their comments and guidance in the conduct of this study.

1 National Institute for Occupational Safety and Health. Criteria for a recommended standard. Occupational exposure to diisocyanates. Cincinnati, OH: NIOSH, 1978. (DHEW (NIOSH) Publ No 78-215.)

2 Bernstein DI, Korbee L, Stauder T, et al. Clinical aspects of allergic disease: The low prevalence of occupational asthma and antibody-dependent sensitization to diphenylmethane diisocyanate in a plant engineered for minimal exposure to diisocyanates. F Allergy Clin Immunol 1993;92:387-96.

3 Bugler, J, Clark RL, Hill ID, et al. The acute and long-term respiratory effects of aromatic di-isocyanates. A five year longitudinal study of polyurethane foam workers. Manchester: International Isocyanate Institute, May, 1991. (III Report 10848.)

4 Jones RN, Rando RJ, Glindmeyer HW, et al. Abnormal lung function in polyurethane foam producers. Weak relationfunction in polyurethane foam producers. Weak relationship to toluene diis

5 Meredith SK, Taylor VM, McDonald JC. Occupational respiratory disease in the United Kingdom 1989: a report to the British Thoracic Society and the Society of Occupational Medicine by the SWORD project group. $\mathrm{Br} F$ Ind Med 1989;48:292-8.

6 Provencher S, Labrèche FP, DeGuire L. Physician-based surveillance system for occupational respiratory dieseases: the experience of PROPULSE, Québec, Canada. Occup Environ Med 1997;54:272-6.

7 Rosenman KD, Reilly MJ, Kalinowski DJ. A state-based surveillance system for work-related asthma. J Occup Environ Med 1997;39:415-25.

8 Straßburger KU, Will W, Zober A. Allergisches Berufsasthma (BK-Nr. 4301) in Deutschland. Auswertung der Berufskrankheiten-Dokumentationsdaten 1989-1993. Ar beitsmed Sozialmed Umweltmed 1996;31:461-7.

9 Wang J, Huang P, Lin J, et al. Occupational asthma due to toluene diisocyanate among velcro-like tape manufacturtoluene diisocyanate among velc
ers. Am f Ind Med 1988;14:73-8.

10 Weill $\mathrm{H}$, Butcher B, Dharmarajan V, et al. Respiratory and immunologic evaluation of isocyanate exposure in a new manufacturing plant. Cincinnati, OH: Department of Health and Human Services (NIOSH), 1981. (Publ No 81-125.)

11 Clark RL, Bugler J, McDermott M, et al. An epidemiology study of lung function changes of toluene diisocyanate foam workers in the United Kingdom. Int Arch Occup Environ Health 1998;71:169-79.
12 Diem JE, Jones RN, Hendrick DJ, et al. Five year longitudinal study of workers employed in a new toluene
diisocyanate manufacturing plant. Am Rev Respir Dis 1982; 126:420-8.

13 Ott MG. Mortality experience among Louisiana chemical manufacturing employees, 1957-92. F La State Med Soc 1996;148:260-6.

14 Reilly DA. A test paper method for determination of tolylene di-isocyanate vapours in air. Analyst 1968;93:17885.

15 Dharmarajan V, Rando RJ. Critical evaluation of continuous monitors for toluene diisocyanate. Am Ind Hyg Ass f 1980; 41:869-78.

16 Levine SP, Hillig KJD, Dharmarajan V, et al. Critical review of sampling, analysis, and monitoring for TDI and MDI. Am Ind Hyg Assoc $\mathcal{F}$ 1995;6:581-9.

17 Matherne RN, Lubs PL, Kerfoot EJ. The development of a passive dosimeter for immediate assessment of phosgene exposures. Am Ind Hyg Ass f 1981;42:681-4.

18 American Thoracic Society. Lung function testing: selection of reference values and interpretative strategies. Am Rev Respir Dis 1991;144:1202-18.

19 Kaplan EL, Meier P. Non-parametric estimation from incomplete observations. Fournal of the American Statistical Association 1958;53:457-81.

20 Baur X, Huber H, Degens PO, et al. Relation between occupational asthma case history, bronchial methacholine challenge, and specific challenge test in patients with suspected occupational asthma. Am f Ind Med 1998;33:114-22.

21 Moscato G, Dellabianca A, Vinci G, et al. Toluene diisocyanate-induced asthma: clinical findings and bronchial responsiveness studies in 113 exposed subjects with work-related respiratory symptoms. f Occup Med 1991;33: $720-5$

22 Leroyer C, Malo J-L, Infante-Rivard C, et al. Changes in airway function and bronchial responsiveness after acute occupational exposure to chlorine leading to treatment in a first aid unit. Occup Environ Med 1998;55:356-9.

23 Ware JH, Dockery DW, Louis TA, et al. Longitudinal and cross-sectional estimates of pulmonary function decline in never-smoking adults. Am $\mathcal{f}$ Epidemiol 1990;132:685-700.

24 Wang M-L, McCabe L, Hankinson L, et al. Longitudinal and cross-sectional analyses of lung function in steelworkers. Am ₹ Respir Crit Care Med 1996;153:1907-13.

25 Lange P, Parner J, Vestbo J, et al. A 15-year follow-up study of ventilatory function in adults and asthma. $N$ Engl f Med 1998:339:1194-200.

26 Musk AW, Peters JM, Berstein L. Absence of respiratory effects in subjects exposed to low concentrations of TDI and MDI: a reevaluation. $\mathcal{f}$ Occup Med 1985;27:917-20.

\section{Occupational and Environmental Medicine - http://www.occenvmed.com}

Visitors to the world wide web can now access Occupational and Environmental Medicine either through the BMJ Publishing Group's home page (http://www.bmjpg.com) or directly by using its individual URL (http://www.occenvmed.com). There they will find the following:

- Current contents list for the journal

- Contents lists of previous issues

- Members of the editorial board

- Subscribers' information

- Instructions for authors

- Details of reprint services.

A hotlink gives access to:

- BMJ Publishing Group home page

- British Medical Association website

- Online books catalogue

- BMJ Publishing Group books.

The web site is at a preliminary stage and there are plans to develop it into a more sophisticated site. Suggestions from visitors about features they would like to see are welcomed. They can be left via the opening page of the BMJ Publishing Group site or, alternatively, via the journal page, through "about this site". 